\title{
Experimental Study of Densification Effect on Al 2024 Plasma Electrolytic Oxidation Film
}

Xinghua Guo, Keqin Du*, Quanzhong Guo, Yong Wang, Chuan Wang, Fuhui Wang

Laboratory for Corrosion and Protection, Institute of Metal Research, Chinese Academy of Science, Shenyang, China, 110000

*E-mail: kqdu@imr.ac.cn

doi: $10.20964 / 2016.09 .48$

Received: 6 June 2016 / Accepted: 12 July 2016 / Published: 7 August 2016

This paper explored the densification effect on the plasma electrolytic oxidation (PEO) film coated on Al substrate under the transient self-feedback control mode. Film compactness and microstructure uniformity were carried out by different surface analysis and testing instruments. The results showed that the high-frequency carrier waveform kept a reasonable control on plasma discharge intensity during different stages, inhibited concentrated plasma discharge, prevented the mullite formation, promoted $\gamma \rightarrow \alpha \quad \mathrm{Al}_{2} \mathrm{O}_{3}$ phase transition sufficiently, and refined the $\alpha-\mathrm{Al}_{2} \mathrm{O}_{3}$ grain distribution. These advantages basically stop the crack and defect generation and improve obviously the PEO film compactness and microstructure uniformity.

Keywords: Ceramics; Arc discharges; X-ray diffraction topography; Phase transitions

\section{$\underline{\text { FULL TEXT }}$}

(C) 2016 The Authors. Published by ESG (www.electrochemsci.org). This article is an open access article distributed under the terms and conditions of the Creative Commons Attribution license (http://creativecommons.org/licenses/by/4.0/). 